\title{
Establishment and characterization of a human retinal pericyte line: A novel tool for the study of diabetic retinopathy
}

\author{
ELENA BERRONE ${ }^{1}$, ELENA BELTRAMO $^{1}$, STEFANO BUTTIGLIERI $^{1}$, SONIA TARALLO $^{1}$, \\ ARTURO ROSSO $^{1}$, HANS-PETER HAMMES ${ }^{2}$ and MASSIMO PORTA ${ }^{1}$ \\ ${ }^{1}$ Department of Internal Medicine, University of Turin, Corso Dogliotti 14, I-10126 Torino, Italy; ${ }^{2} 5$ th Medical Department, \\ University Hospital Mannheim, University of Heidelberg, Theodor-Kutzer-Ufer 1-3, D-68167 Mannheim, Germany
}

Received November 14, 2008; Accepted December 30, 2008

DOI: 10.3892/ijmm_00000141

\begin{abstract}
Loss of pericytes from retinal microvessels is one of the key events in the natural history of diabetic retinopathy. Cultured human retinal pericytes would constitute an extremely useful tool for the study of the early events in the pathogenesis of this complication, but, due to legal and ethical issues, pericytes of animal origin have been mostly used so far for in vitro assays. We aimed at establishing an immortalized human retinal pericyte (HRP) line, as a species-specific model to investigate the pericyte-related aspects of diabetic retinopathy. Primary human retinal pericytes (WT-HRP) were immortalized through electroporation with a plasmid vector containing the Bmi-1 oncogene that induces telomerase activity, resulting in the establishment of a permanent pericyte line $\left(\mathrm{Bmi}^{-H R P}{ }^{\circledR}\right)$, which showed telomerase activity and facilitated propagation. The immortalized cells were characterized for typical pericyte morphology and marker expression. Immunofluorescence studies demonstrated that Bmi-HRP maintain the same morphology and express the typical markers of wild-type pericytes. The response of the cell line to high glucose damaging stimulus was also evaluated, as senescence-associated B-galactosidase activity and cell proliferation and a clear negative effect of high glucose on Bmi-HRP proliferation and senescence, in line with the characteristic response of wild-type cells, was observed. The
\end{abstract}

Correspondence to: Dr Elena Beltramo, Department of Internal Medicine, University of Turin, Corso Dogliotti 14, I-10126 Torino, Italy

E-mail: elena.beltramo@unito.it

Abbreviations: $\alpha$-SMA, $\alpha$-smooth muscle actin; Bmi-HRP, immortalized human retinal pericytes; DAPI, 4',6-diamidino-2phenilindolo-chloridrate; DMEM, Dulbecco's modified Eagle's medium; FCS, foetal calf serum; hTERT, human telomerase reverse transcriptase; NG-2, neuron glial-2; PBS, phosphate-buffered saline; PDGF-B, platelet-derived growth factor-B; PDGFR- $\beta$, plateletderived growth factor receptor- $\beta$; WT-HRP, primary human retinal pericyte

Key words: human retinal pericyte, telomerase, Bmi-1, immortalization, cell line, diabetic retinopathy combination of infinite proliferation capability and stable differentiation potential makes our Bmi-HRP line a promising candidate model to study pathogenic mechanisms and therapeutic applications in diabetic retinopathy.

\section{Introduction}

The retina has the highest pericyte density in the human body and these cells appear to play a crucial role in the development of diabetic retinopathy (1). One of the earliest identified lesions in the diabetic retina is pericyte loss (2). Although many believe 'pericyte drop-out' to be the result of high glucose damage (3), the exact mechanisms which underlie their disappearance have not been elucidated.

Loss of pericytes has great consequences on capillary remodelling and may cause the first abnormalities that are observed clinically. Pericytes in capillaries act similarly to smooth muscle cells in larger vessels, regulating vascular tone and perfusion pressure. Moreover, pericytes are closely linked to endothelial cells and may regulate their proliferation, while receiving nourishment and growth factors from them $(4,5)$.

To investigate the pathophysiological role of pericytes, primary bovine or rat cells have been used so far for in vitro studies but some observations of ours (unpublished data) and from others $(6,7)$ suggest that human and bovine retinal pericytes may behave differently in experimental conditions designed to mimic the diabetic milieu.

Normal human cells divide only a limited number of times before entering a state of replicative senescence (8). The signal for senescence is attributed to chromosomal end replication problems, due to shortening of the telomere within each cell division (9).

Moreover, primary cells may alter their properties during passages in vitro and differ each time they are extracted from living tissues. Finally, shortage of human material due to legislative and ethic issues in certain countries prevent researchers from using relevant cells from human sources.

Several methods are described to extend cell proliferation, including ectopic expression of viral oncogenes or spontaneous transformation (10-12). However, cells thus immortalized frequently loose cell-specific differentiation properties and differ considerably from their wild (primary) counterparts. Addition of telomeres at the chromosomal ends by activating 
the ribonuclease protein enzyme telomerase, through the expression of the catalytic subunit human telomerase reverse transcriptase (hTERT) is also used (13). The oncogene Bmi-1 was shown to extend the life span of primary human fibroblasts (14) and to immortalize human cells through activation of endogenous hTERT transcription and induction of telomerase activity $(15,16)$.

Our objective was to establish a human retinal pericyte (HRP) line, which preserves the functional and morphological phenotype of wild-type cells, to investigate the pathogenesis of diabetic retinopathy with a species-specific model.

\section{Materials and methods}

Cell cultures. Wild-type HRP (WT-HRP) at second passage, obtained from a 55-year-old non-diabetic white man, were purchased from Cambrex Bio Science (Rockland, ME, USA). Both types of pericytes were maintained in DMEM $5.6 \mathrm{mmol} / \mathrm{l}$ glucose with $20 \%$ FCS in primary cultures and $10 \%$ in secondary cultures (subconfluent cultures were split 1:3). All reagents for cell cultures were purchased from Sigma-Aldrich, St. Louis, MO, USA.

Immortalization of human pericytes. Exponentially growing WT-HRP cells cultured between the 2 nd and 5 th passage were trypsinized and resuspended in growth medium. Electroporation was performed with a Gene Pulser (BioRad, Hercules, CA, USA), subjecting $100 \mu 1$ of exponentially growing 5th passage WT-HRP suspension $\left(\sim 10^{4}-10^{5}\right.$ cells $)$ at $180 \mathrm{~V}$ for $20 \mathrm{msec}$ with $5 \mu \mathrm{g}$ of vector pcDNA4/TO (Invitrogen, Carlsbad, CA, USA), carrying the subcloned transcription factor gene Bmi-1. The 980-bp transcript for Bmi-1 (accession no.: NM 005180) encoding the start codon and the stop codon were inserted in the plasmid using internal restriction sites EcoRI and XhoI. Cells were selected with zeocin $(5 \mu \mathrm{g} / \mathrm{ml})$ for 3 weeks, during which only the cells containing the plasmid continued to proliferate. Different clones of zeocin-selected cells were developed for characterization and high glucose experiments. The resulting cell line was patented (Italian patent, no. TO2007A000674, Sept. 26, 2007) and code-named Bmi-HRP ${ }^{\circledR}$.

hTERT $m$ RNA expression. Total RNA was isolated from WTHRP and Bmi-HRP, using the High Pure RNA isolation kit (Roche, Mannheim, Germany). Contaminating DNA was removed using DNase I. The yield of each RNA sample was checked spectrophotometrically at $260 \mathrm{~nm}$. RT-PCR was performed with $0.5 \mu \mathrm{g}$ RNA using the Qiagen OneStep RTPCR kit (Qiagen GmbH, Hilden, Germany). The assay was designed for multiplex RT-PCR, each reaction set containing primers for hTERT and for $ß$-actin as an internal control, using the Quantum RNA B-actin internal standards (Ambion, Austin, TX, USA). Amplification was performed using the following cycling parameters: hold at $50^{\circ} \mathrm{C}, 30 \mathrm{~min}$ (RT step); hold at $95^{\circ} \mathrm{C}, 15 \mathrm{~min}$ (hot start to PCR); 35 cycles of $95^{\circ} \mathrm{C}$ $(30 \mathrm{sec}) / 60^{\circ} \mathrm{C}(30 \mathrm{sec}) / 72^{\circ} \mathrm{C}(1 \mathrm{~min})$; followed by a final hold at $72^{\circ} \mathrm{C}$ for $10 \mathrm{~min}$. The RT-PCR products were visualized by electrophoresis in $2 \%$ agarose gels containing $1 \mu \mathrm{g} / \mathrm{ml}$ ethidium bromide and were quantified using an image analysis system (1D image analysis system, Kodak, Rochester, NY, USA). Primers used for hTERT were: 5 ' primer, GGGGAAGCATGCCAAGCTCT; 3' primer, GGTTGAAG TTGGAGATGCCAATAGC, which generated a 218-bp product.

Determination of telomerase activity. Telomerase activity was determined using the telomerase repeat amplification protocol assay performed with the TRAPeze telomerase detection kit (Chemicon, Temecula, CA, USA), according to the manufacturer's instructions. Cells were grown to $70-80 \%$ confluence and lysed with CHAPS buffer. A lysate volume equal to 5000 cells was used for each reaction. Samples heated at $85^{\circ} \mathrm{C}$ for $10 \mathrm{~min}$ were used as negative controls, being a positive control included in the kit. Electrophoresis was performed on a $12 \%$ non-denaturing acrylamide gel, stained with $1 \mu \mathrm{g} / \mathrm{ml}$ ethidium bromide and bands were visualized using the Kodak 1D image analysis system.

Senescence-associated $\beta$-galactosidase activity. Subconfluent Bmi-HRP and WT-HRP were analysed using the Senescence ß-galactosidase staining kit (Cell Signaling Technology Inc., Danvers, MA, USA) according to the manufacturer's protocol, after 30 passages for Bmi-HRP and 10 passages for WT-HRP. Cells were grown in normal $(5.6 \mathrm{mmol} / \mathrm{l})$ or high $(28 \mathrm{mmol} / \mathrm{l})$ D-glucose for 3 days and then covered with $70 \%$ glycerol and evaluated by light microscopy. They were considered senescent if $>90 \%$ exhibited the characteristic blue senescenceassociated $\beta$-galactosidase staining.

Growth kinetic assay. After 30 passages in culture for BmiHRP and 10 passages for WT-HRP, cells were analysed for growth kinetics using an automated cell counter (New Brunswick Scientific, Edison, NJ, USA), following incubation in physiological $(5.6 \mathrm{mmol} / \mathrm{l})$ or high $(28 \mathrm{mmol} / \mathrm{l}) \mathrm{D}$-glucose for $3,6,9,12$ and 15 days.

Morphology and immunocytochemical characterization. To verify that Bmi-HRP maintained the same morphology as WT-HRP, cells were observed by phase-contrast light microscopy, after 30 passages in culture for Bmi-HRP and 5 passages for WT-HRP. Moreover, cells were stained with the pericyte markers $\alpha$-smooth muscle actin ( $\alpha$-SMA), desmin, platelet-derived growth factor receptor- $\beta$ (PDGFR- $\beta$ ) and neuron glial-2 (NG-2) by immunofluorescence. Human microvascular endothelial cells (HMEC, Cambrex), nonexpressing $\alpha$-SMA and NG-2, were used as cell negative controls. Cells were cultured up to $80 \%$ confluence on Chamber slide system (Lab-Tek, Nalge Nunc International, Naperville, IL, USA), then fixed for 6 min with methanol at $-20^{\circ} \mathrm{C}$ and blocked in a TritonX100 $(0.05 \%) / \mathrm{BSA} 1 \% /$ PBS1X solution (Sigma) for $30 \mathrm{~min}$ at $4^{\circ} \mathrm{C}$. The antibodies used were: $\alpha$-SMA FITC-conjugated (Sigma), desmin (Santa Cruz Biotechnology, Santa Cruz, CA, USA), PDGFR-ß (Santa Cruz) and NG-2 (Chemicon). Cells were incubated with the primary and the adequate secondary antibodies for $1 \mathrm{~h}$ each at room temperature. Negative controls were performed labelling Bmi-HRP and WT-HRP with the relevant secondary antibodies only. Finally, the labelled cells were sealed with a solution containing DAPI (Vector Laboratories Ltd., 

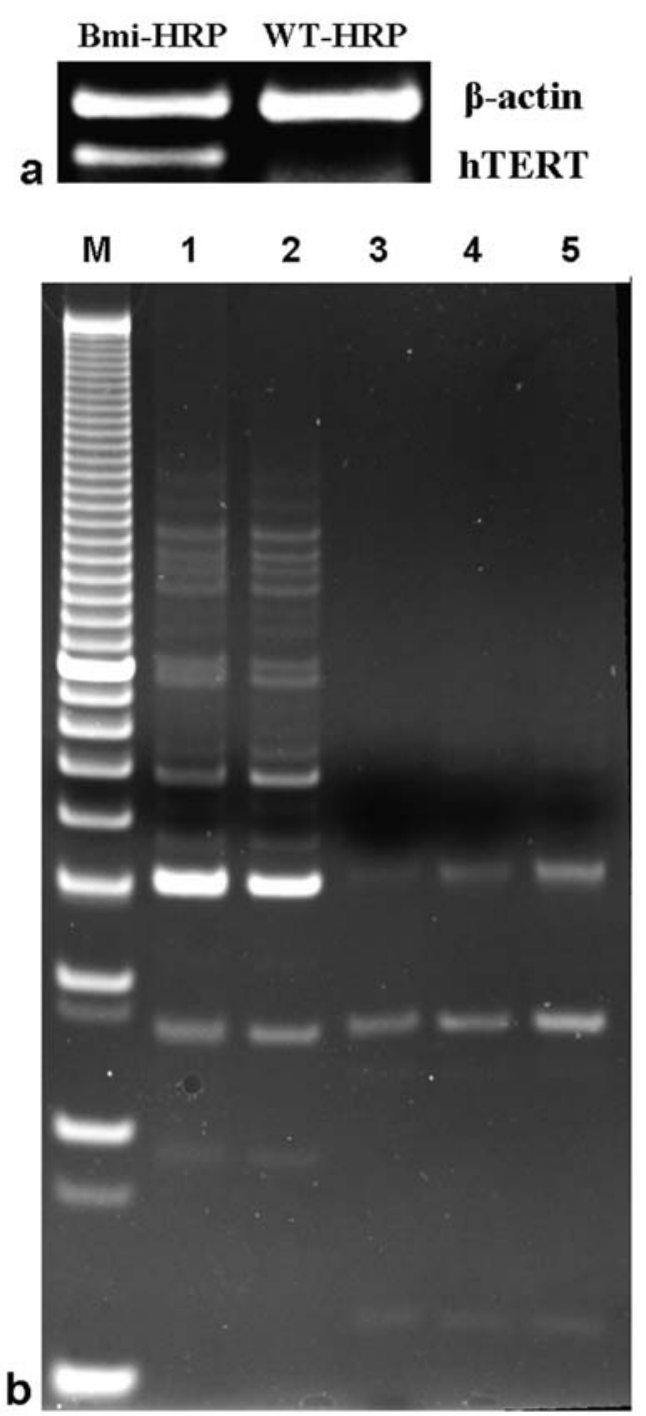

Figure 1. hTERT mRNA expression (a) and activity (b). (a) hTERT mRNA was expressed in Bmi-HRP ${ }^{\circledR}$ and undetectable in WT-HRP. (b) M. Marker; 1) Positive control cells from kit; 2) Bmi-HRP, 3) Bmi-HRP heated at $85^{\circ} \mathrm{C}$ for $10 \mathrm{~min}$; 4) WT-HRP; 5) WT-HRP heated at $85^{\circ} \mathrm{C}$ for $10 \mathrm{~min}$. In heated samples (negative controls) telomerase activity was inactivated. Telomerase activity was overexpressed in Bmi-HRP but undetectable in WT-HRP.

Peterborough, UK) and observed with a fluorescent microscope at $\times 400$ magnification.

\section{Results}

hTERT mRNA expression and telomerase activity. We analysed Bmi-HRP ${ }^{\circledR}$ and WT-HRP for the expression of the endogenous hTERT gene. RT-PCR confirmed that Bmi-1 transfection led to the activation of hTERT gene transcription, which instead was undetectable in non-transfected WT-HRP (Fig. 1a). The TRAPeze assay demonstrated that Bmi-HRP continue to show telomerase activity for $\sim 30$ passages, while WT-HRP had no detectable telomerase activity (Fig. 1b).

Senescence-associated $\beta$-galactosidase activity and growth kinetic assay. Primary WT-HRP entered senescence after 10 passages in physiological glucose, as demonstrated by the strong blue reaction product of B-galactosidase (Fig. 2a), a
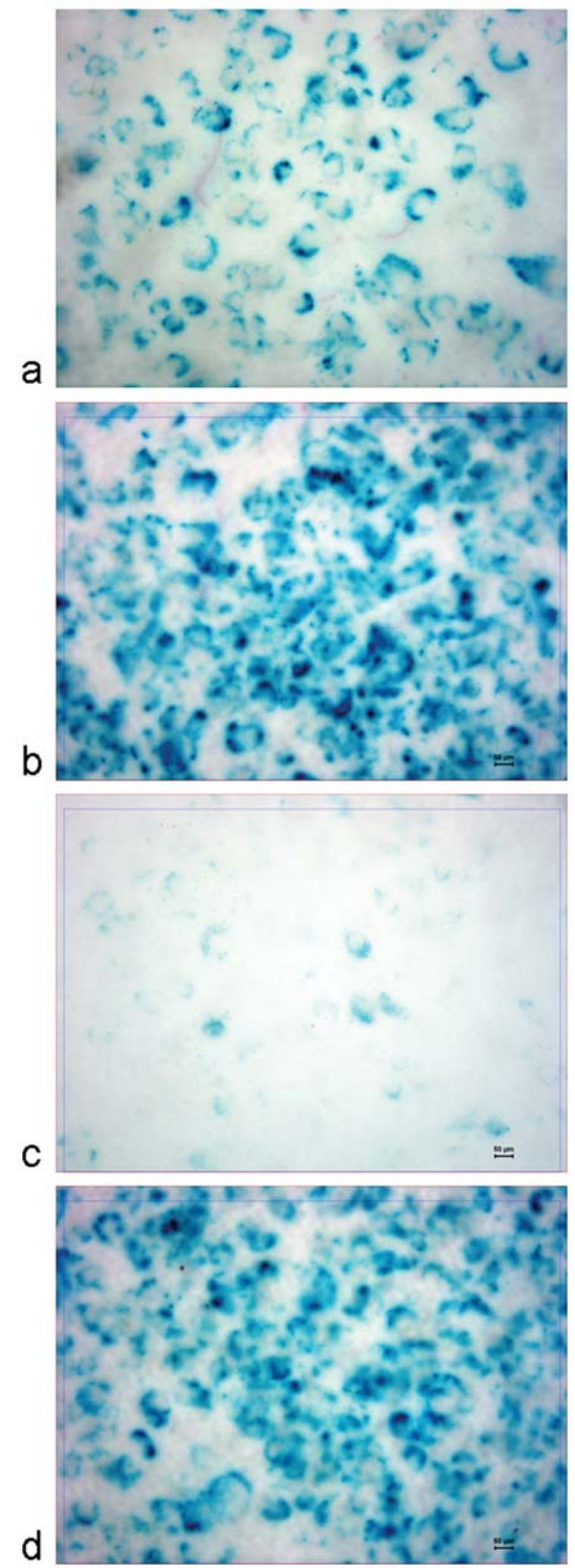

Figure 2. Senescence-associated $\beta$-galactosidase activity of Bmi-HRP ${ }^{\circledR}$ and WT-HRP. B-galactosidase activity was overexpressed in WT-HRP (a) but very low in Bmi-HRP (c), when cells were cultured in physiological glucose $(5.6 \mathrm{mmol} / \mathrm{l})$. In contrast, in high glucose conditions $(28 \mathrm{mmol} / \mathrm{l})$, both WT-HRP (b) and Bmi-HRP (d) produced a strong blue reaction product.

biomarker associated with cellular aging, together with an interruption of cell proliferation (Fig. 3). On the contrary, Bmi-HRP continued to proliferate after 30 passages in 


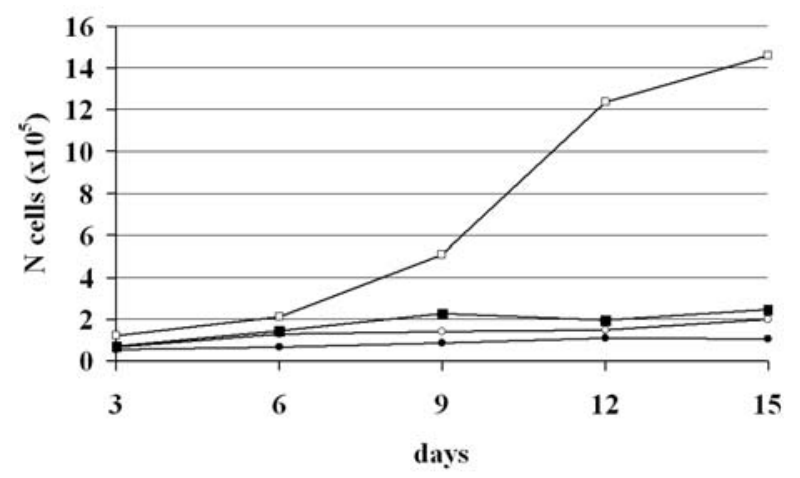

Figure 3. Growth kinetic curves of Bmi-HRP ${ }^{\circledR}$ and WT-HRP, in physiological $(5.6 \mathrm{mmol} / \mathrm{l})$ and high $(28 \mathrm{mmol} / \mathrm{l})$ glucose. Means of six experiments. White squares, Bmi-HRP in physiological glucose; black squares, Bmi-HRP in high glucose; white circles, WT-HRP in physiological glucose; black circles, WT-HRP in high glucose. Immortalized pericytes maintain their proliferation capability after 30 passages in culture, as compared to younger WT-HRP, but are sensible to the high glucose insult.

physiological glucose (Fig. 3), with a very low activity of senescence-associated B-galactosidase (Fig. 2c). When cultured in high glucose conditions, Bmi-HRP at passage 30 showed low proliferation (Fig. 3) and marked signs of senescence (Fig. 2d), similarly to WT-HRP under the same conditions (Figs. 2b and 3).

Morphology and pericyte marker characterization. Bmi-HRP maintained the characteristic pericyte morphology after 30 passages (Fig. 4a), as compared with younger (5th passage) primary WT-HRP (Fig. 4b). Both Bmi-HRP and WT-HRP showed the same expression of pericyte markers such as $\alpha$-SMA (Fig. 4e-g), desmin (Fig. 4i-k), PDGFR- 3 (Fig. 4m-o) and NG-2 (Fig. 4q-s), demonstrating that Bmi-HRP retain the typical phenotype associated with human pericytes in the adult retina. HMEC, used as a negative control, did not stain with either $\alpha$-SMA (Fig. 4c) or NG-2 (Fig. 4d).

\section{Discussion}

Pericytes play an important role in the onset and progression of diabetic retinopathy and the establishment of a reliable human cell model could help answering unresolved questions on its pathogenesis. Our results suggest that our novel immortalized cell line (Bmi-HRP) retains the same characteristic morphology and expression of pericyte markers as WT-HRP, whereas mRNA expression and activity of hTERT were observed only in Bmi-HRP. Compared with WTHRP, Bmi-HRP showed no activity of senescence-associated B-galactosidase and enhanced proliferation. Response of BmiHRP to high glucose is very similar to that of wild-type cells, suggesting that the immortalized line is able to undergo apoptosis in response to this stress stimulus.

Replicative senescence represents a barrier that a cell must overcome in order to become immortal (17). Telomerase regulates the proliferation of human somatic cells through telomere maintenance and there is evidence that human somatic cells, endothelial cells, retinal pigment epithelium, and T-lymphocytes can be immortalized or have their in vitro lifespan extended by the ectopic expression of hTERT (18-23).
Moreover, an increase in replicative capability is not associated with alterations of their normal differentiated properties in vitro or in vivo (24). Previous studies demonstrate that also Bmi-1 is able to overexpress hTERT and activate telomerase, thus bypassing senescence (15-17).

In the present study, an immortalized human retinal pericyte cell line, called Bmi-HRP, in which the telomerase expression and activity was detectable, was established by the introduction of the oncogene Bmi-1. This finding is important for pericyte biology research because primary cells usually become senescent within few passages, and their short lifespan period makes it difficult to obtain sufficient quantities of cells for experiments. Telomerase activity extended the replicative lifespan of Bmi-HRP at least up to the 30th passage and prevented their senescence in normal glucose, whereas WTHRP had a limited lifespan and spontaneously became senescent within 10 passages.

Our analysis of the phenotypic pattern revealed that BmiHRP retained pericyte-specific characteristics in in vitro cultures, including WT-HRP cell morphology and immunostaining of antigens commonly used as pericyte markers, such as $\alpha$-SMA, desmin, PDGFR- $\beta$ and NG-2 (25-28). Only two types of cells are present in retinal microvessels: endothelium and pericytes. Even if no specific molecular markers for pericytes are available, we have ruled out the possibility of endothelial cell contamination because our cells (both primary WT-HRP and post-transfection Bmi-HRP) show immunostaining for $\alpha$-SMA and NG-2 (Fig. 3e, g, q, and s), which is not to be found in EC (Fig. 3c and d).

Contraction and relaxation of pericytes contribute to the regulation of blood flow at the microvascular level, similar to smooth muscle cells of larger vessels (29). The first line of evidence came from the presence of contractile proteins in the pericyte cells, such as $\alpha$-actin and desmin (30). We show that Bmi-HRP express both $\alpha$-actin and desmin, suggesting that this cell line might maintain contractile functions also in vitro.

Pericytes are not only involved in hemodynamic processes but also play an active role in vessel formation. For this reason, the PDGFR- $\beta$ is widely studied among molecules expressed in pericytes. Mice deficient in PDGFR- $\beta$ or its ligand, plateletderived growth factor-B (PDGF-B), have a severely reduced number of pericytes and subsequent hyperdilatation of blood vessels, which causes oedema formation and embryonic lethality (28). Only pericytes positive for PDGFR- $\beta$ could populate the right vascular compartment and complete their cell-development (31). Thus, the Bmi-HRP expression of PDGFR- $\beta$ show that these cells continue to maintain this important differentiated characteristic of WT-HRP, demonstrating that they could be used in studies on angiogenesis. Finally, in both Bmi-HRP and WT-HRP, we observed a positive expression of NG-2 which is also expressed on the surface of pericytes during vasculogenic and angiogenic processes (26).

The effects of diabetes on the pericyte-containing retinal microvasculature are of keen interest because a key feature of diabetic retinopathy is dysfunction and, ultimately, apoptotic death of microvascular cells $(32,33)$. In particular, chronic hyperglycemia is believed to cause pericyte drop-out $(3,4)$. As shown in Fig. 3, WT-HRP after 10 passages in culture, being already in a senescence phase, proliferate neither in 

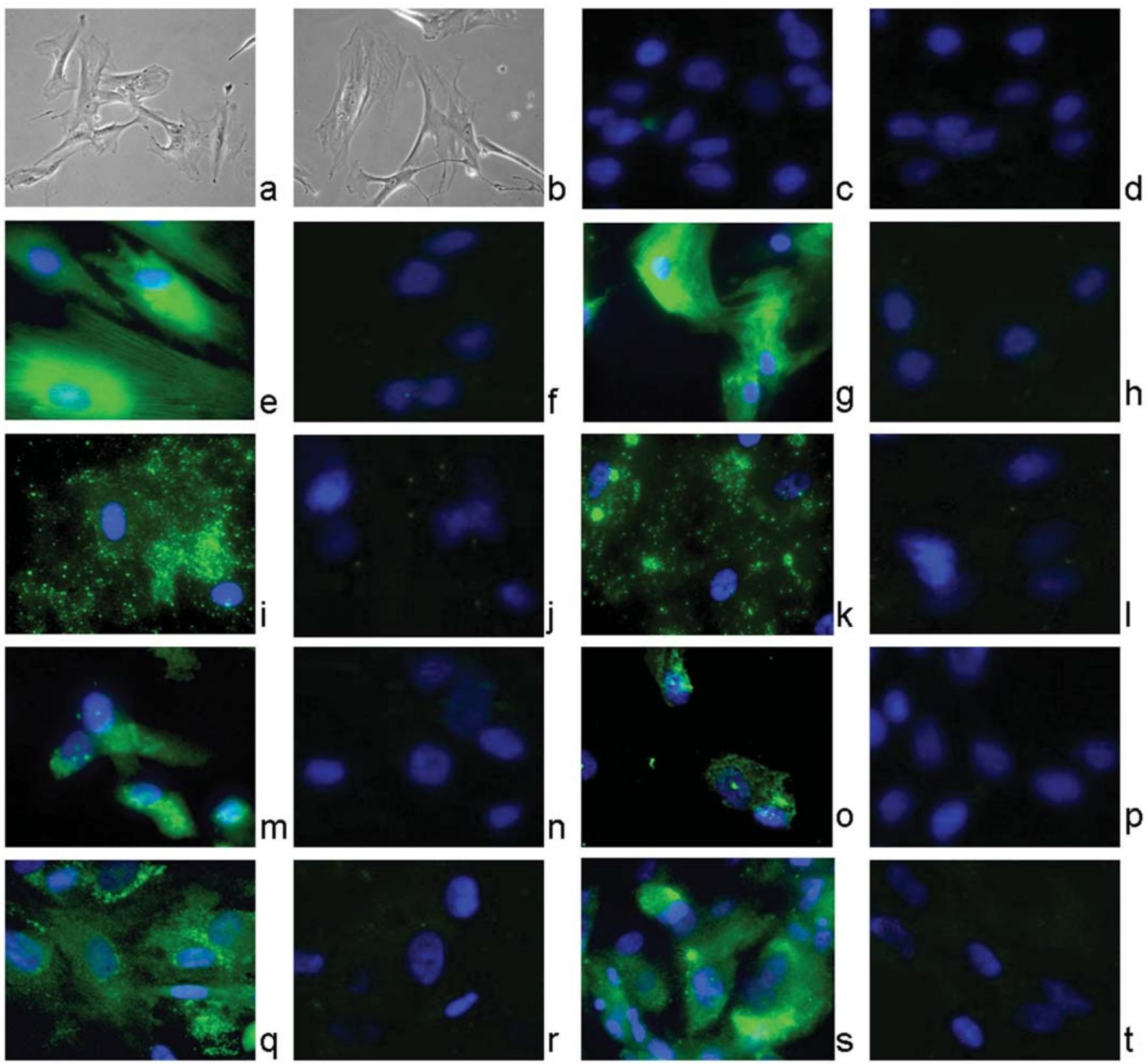

Figure 4. Characterization of Bmi-HRP ${ }^{\circledR}$ and WT-HRP. Morphological comparison between Bmi-HRP (a) and WT-HRP (b). Expression of pericyte markers by immunofluorescence: HMEC marked with (c) anti- $\alpha$-SMA and (d) anti-NG-2 (cell negative controls); Bmi-HRP labelled with (e) anti- $\alpha$-SMA, (i) antidesmin, (m) anti-PDGFR- $\beta$, and (q) anti-NG-2; (f, j, n, r) Bmi-HRP labelled with the relevant secondary antibody only (negative controls); WT-HRP labelled with (g) anti- $\alpha$-SMA, (k) anti-desmin, (o) anti-PDGFR- $\beta$, and (s) anti-NG-2; (h, 1, p, t) WT-HRP labelled with the relevant secondary antibody only (negative controls). Bmi-HRP retain the same morphology and pericyte markers as WT-HRP.

physiological nor in high glucose. On the contrary, Bmi-HRP continue to proliferate even after 30 passages in physiological glucose, but show a reduction in proliferation and high senescence-associated B-galactosidase blue staining, when cultured in high glucose concentrations. This suggests that the immortalized cell line Bmi-HRP is able to undergo senescence in response to stress stimuli, such as elevated glucose concentrations, similarly to young primary human pericytes. Thus, this cell line can be used to study the effects of hyperglycaemia.

In conclusion, we generated a human retinal pericyte line with extended proliferation capability and stable differentiation, together with the ability to be influenced by glucose toxicity. All these characteristics make this line a promising model for the study of pathogenic mechanisms as well as therapeutic applications in diabetic retinopathy or in other important pathophysiological processes, such as angiogenesis and arteriosclerosis.

\section{Acknowledgements}

The authors wish to thank J. Lin, A. Rippert and N. Dietrich of the University Hospital Mannheim (Germany) for their technical assistance. This work was supported by grants from the Compagnia di San Paolo, Turin, and the University of Turin (Fondi ex-60\%). E. Berrone was recipient of an EFSD/ 
Albert Renold Fellowship to complete part of this work in Professor H.P. Hammes' laboratory.

\section{References}

1. Hall AP: Review of the pericyte during angiogenesis and its role in cancer and diabetic retinopathy. Toxicol Pathol 34: 763-775, 2006.

2. Cogan DG and Kubawara T: The mural cell in perspective. Arch Ophthalmol 78: 133-139, 1967.

3. Hammes HP, Lin J, Renner O, Shani M, Lundqvist A, Betsholtz C, Brownlee M and Deutsch U: Pericytes and the pathogenesis of diabetic retinopathy. Diabetes 51: 3107-3112, 2002.

4. Li W, Yanoff M, Liu X and Ye X: Retinal capillary pericyte apoptosis in early human diabetic retinopathy. Chin Med J 110: 659-663, 1997.

5. Armulik A, Abramsson A and Betsholtz C: Endothelial/pericyte interactions. Circ Res 97: 512-523, 2005.

6. Miller AG, Smith DG, Bhat M and Hagaraj RH. Glyoxalase I is critical for human retinal capillary pericyte survival under hyperglycemic conditions. J Biol Chem 2281: 11864-11871, 2006.

7. Agardh CD, Hultberg B, Nayak RC, Farthing-Nayak P and Agardh E: Bovine retinal pericytes are resistant to glucoseinduced oxidative stress in vitro. Antioxid Redox Signal 7: 1486-1493, 2005.

8. Campisi J: Replicative senescence: an old lives' tale? Cell 84: 497-500, 1996.

9. Shay JW and Wright WE: Use of telomerase to create bioengineered tissues. Ann NY Acad Sci 1057: 479-491, 2005.

10. Sarthy VP, Brodjian SJ, Dutt K, Kennedy BN, French RP and Crabb JW: Establishment and characterization of a retina Müller cell line. Invest Ophthalmol Vis Sci 39: 212-216, 1998.

11. Nagai A, Nakagawa E, Hatori K, Choi HB, McLarnon JG, Lee MA and Kim SU: Generation and characterization of immortalized human microglial cell lines: expression of cytokines and chemokines. Neurobiol Dis 8: 1057-1068, 2001.

12. Dunn KC, Aotaki-Keen AE, Putkey FR and Hjelmeland LM: ARPE-19, a human retinal pigment epithelial cell line with differentiated properties. Exp Eye Res 62: 155-169, 1996.

13. Counter CM, Meyerson M, Eaton EN, Ellisen LW, Caddle SD, Haber DA and Weinberg RA: Telomerase activity is restored in human cells by ectopic expression of hTERT (hEST2), the catalytic subunit of telomerase. Oncogene 16: 1217-1222, 1998 .

14. Itahana K, Zou Y, Itahana Y, Martinez JL, Beausejour C, Jacobs JJ, Van Lohuizen M, Band V, Campisi J and Dimri GP: Control of the replicative life span of human fibroblasts by 16 and the polycomb protein Bmi-1. Mol Cell Biol 23: 389-401, 2003.

15. Dimri GP, Martinez JL, Jacobs JJ, Keblusek P, Itahana K, Van Lohuizen M, Campisi J, Wazer DE and Band V: The Bmi-1 oncogene induces telomerase activity and immortalizes human mammary epithelial cells. Cancer Res 62: 4736-4745, 2002.

16. Song LB, Zeng MS, Liao WT, Zhang L, Mo HY, Liu WL, Shao JY, Wu QL, Li MZ, Xia YF, Fu LW, Huang WL, Dimri GP, Band $\mathrm{V}$ and Zeng YX: Bmi-1 is a novel molecular marker of nasopharyngeal carcinoma progression and immortalizes primary human nasopharyngeal epithelial cells. Cancer Res 66: 6225-6232, 2006.
17. Campisi J: Cancer, aging and cellular senescence. In Vivo 14: 183-188, 2000.

18. Deissler H, Deissler H, Lang GK and Lang GE: Generation and characterization of iBREC: novel hTERT-immortalized bovine retinal endothelial cells. Int J Mol Med 16: 65-70, 2005.

19. Bodnar AG, Ouellette M, Frolkis M, Holt SE, Chiu CP Morin GB, Harley CB, Shay JW, Lichtsteiner S and Wright WE: Extension of life-span by introduction of telomerase into normal human cells. Science 279: 349-352, 1998.

20. Vaziri H and Benchimol S: Reconstitution of telomerase activity in normal human cells leads to elongation of telomeres and extended replicative life span. Curr Biol 8: 279-282, 1998.

21. Rambhatla L, Chiu CP, Glickman RD and Rowe-Rendleman C: In vitro differentiation capacity of telomerase immortalized human RPE cells. Invest Ophthalmol Vis Sci 43: 1622-1630, 2002.

22. Yang J, Chang E, Cherry AM, Bangs CD, Oei Y, Bodnar A Bronstein A, Chiu CP and Herron GS: Human endothelial cell life extension by telomerase expression. J Biol Chem 274: 26141-26148, 1999.

23. Rufer N, Migliaccio M, Antonchuk J, Humphries RK, Roosnek E and Lansdorp PM: Transfer of the human telomerase reverse transcriptase (TERT) gene into T lymphocytes results in extension of replicative potential. Blood 98: 597-603, 2001.

24. Jiang XR, Jimenez G, Chang E, Frolkis M, Kusler B, Sage M, Beeche M, Bodnar AG, Wahl GM, Tlsty TD and Chiu CP: Telomerase expression in human somatic cells does not induce changes associated with a transformed phenotype. Nat Genet 21: 111-114, 1999.

25. Wallow IH and Burnside B: Actin filaments in retinal pericytes and endothelial cells. Invest Ophtalmol Vis Sci 19: 1433-1441, 1980.

26. Stallcup WB: The NG2 proteoglycan: past insights and future prospects. J Neurocytol 31: 423-435, 2002.

27. Gerhardt $\mathrm{H}$ and Betsholtz $\mathrm{C}$ : Endothelial-pericyte interactions in angiogenesis. Cell Tissue Res 314: 15-23, 2003.

28. Bjarnegård M, Enge M, Norlin J, Gustafsdottir S, Fredriksson S, Abramsson A, Takemoto M, Gustafsson E, Fassler R and Betsholtz C: Endothelium-specific ablation of PDGFB leads to pericyte loss and glomerular, cardiac and placental abnormalities. Development 131: 1847-1857, 2004.

29. Rucker HK, Wynder HJ and Thomas WE: Cellular mechanisms of CNS pericytes. Brain Res Bull 51: 363-369, 2000.

30. Wallow IH and Burnside B: Actin filaments in retinal pericytes and endothelial cells. Invest Ophthalmol Vis Sci 19: 1433-1441, 1980.

31. Crosby JR, Seifert RA, Soriano P and Bowen-Pope DF: Chimaeric analysis reveals role of Pdgf receptors in all muscle lineages. Nat Genet 18: 385-388, 1998.

32. Mizutani M, Kern TS and Lorenzi M: Accelerated death of retinal microvascular cells in human and experimental diabetic retinopathy. J Clin Invest 97: 2883-2890, 1996.

33. Beltramo E, Berrone E, Buttiglieri S and Porta M: Thiamine and benfotiamine prevent increased apoptosis in endothelial cells and pericytes cultured in high glucose. Diabetes Metab Res Rev 20: 330-336, 2004. 